\title{
The anticancer effect of saffron in two p53 isogenic colorectal cancer cell lines
}

\author{
Khuloud Bajbouj ${ }^{1}$, Jan Schulze-Luehrmann², Stefanie Diermeier ${ }^{2}$, Amr Amin ${ }^{1,3}$ and Regine Schneider-Stock ${ }^{1,2^{*}}$
}

\begin{abstract}
Background: Saffron extract, a natural product, has been shown to induce apoptosis in several tumor cell lines. Nevertheless, the p53-dependency of saffron's mechanism of action in colon cancer remains unexplored.

Material and methods: In order to examine saffron's anti-proliferative and pro-apoptotic effects in colorectal cancer cells, we treated two p53 isogenic HCT116 cell lines (HCT wildtype and HCT p53-/-) with different doses of the drug and analyzed cell proliferation and apoptosis in a time-dependent manner. MTT viability and crystal violet assays were performed in order to determine the effective dose of saffron on both cell lines. The cell cycle progress was examined by Flow cytometric analysis. Apoptosis was assessed using Annexin-Pl-staining and Western Blotting for caspase 3 and PARP cleavage. Autophagy was determined by Western Blotting of the light chain 3 (LC3)-II and Beclin 1 proteins. The protein content of phospho-H2AX (YH2AX), a sensor of DNA double strand breaks, was also analyzed by Western Blotting.
\end{abstract}

Results: Saffron extract induced a p53-dependent pattern of cell cycle distribution with a full G2/M stop in HCT116 p53 wildtype cells. However, it induced a remarkable delay in S/G2 phase transit with entry into mitosis in HCT116 p53 -/- cells. The apoptotic Pre-G1 cell fraction as well as Annexin V staining and caspase 3 cleavage showed a more pronounced apoptosis induction in HCT116 p53 wildtype cells. Obviously, the significantly higher DNA-damage, reflected by $\mathrm{\gamma H} 2 \mathrm{AX}$ protein levels in cells lacking p53, was coped by up-regulation of autophagy. The saffron-induced LC3-II protein level was a remarkable indication of the accumulation of autophagosomes, a response to the cellular stress condition of drug treatment.

Conclusions: This is the first study showing the effect of saffron in HCT116 colorectal cancer cells with different p53 status. Saffron induced DNA-damage and apoptosis in both cell lines. However, autophagy has delayed the induction of apoptosis in HCT116 p53 -/- cells. Considering the fact that most tumors show a functional p53 inactivation, further research is needed to elucidate the long-term effects of saffron in p53 -/- tumors.

\section{Background}

Colorectal cancer is one of the most common malignancies in the world with approximately one million new cases diagnosed every year [1]. The high incidence of the disease and its associated morbidity and mortality has brought colorectal cancer to the center of cancer research, namely its aetiology, diagnosis and treatment. In the last few decades, the acquired knowledge of the molecular

\footnotetext{
* Correspondence: regine.schneider-stock@uk-erlangen.de

'Biology Department, Faculty of Science, UAE University, Al-Ain, United Arab Emirates

${ }^{2}$ Experimental Tumorpathology, Institute of Pathology, University of Erlangen-Nürnberg, Universitätsstrasse 22, Erlangen 91054, Germany Full list of author information is available at the end of the article
}

biology of the disease and the development of new therapeutic strategies has been steadily increasing [2].

Natural products encompass three main categories of compounds, phenylpropanoids, isoprenoids, and alkaloids, which are widely distributed in plant foods and medicinal herbs [3-5]. This large array of molecules is crucial to human nutrition and health. Plant-derived foodstuffs and beverages also constitute the so-called functional foods and beverages, which include mainly fruits, vegetables, herbs and spices [6]. Saffron, the dried styles (stigmata) of Crocus sativus L. flowers, is widely known as a spice and its uses in traditional medicine are well established and date back nearly 3000 years, spanning many continents, civilizations, and cultures $[7,8]$.

\section{Biomed Central}

(c) 2012 Bajbouj et al.; licensee BioMed Central Ltd. This is an Open Access article distributed under the terms of the Creative Commons Attribution License (http://creativecommons.org/licenses/by/2.0), which permits unrestricted use, distribution, and reproduction in any medium, provided the original work is properly cited. 
Saffron is characterized by its unique aroma, color, and flavor and is cultivated in various parts of the world, particularly in Iran and Spain [9,10]. Cancer chemoprotection is based on the use of exogenous phytochemicals to enhance endogenous mechanisms against various stages of cancer development. There has been a great deal of interest in exploring the chemopreventive properties of herbs and plants. For instance, saffron extracts have the potential to make a major contribution to effective chemopreventive therapy [11].

Studies in animal models and with cultured human malignant cell lines have demonstrated anti-tumor and anti-cancer activities of saffron [12-17]. Different hypotheses for anti-carcinogenic and anti-tumor effects of saffron and its ingredients have been proposed, including (a) inhibition of synthesis of DNA and RNA, but not protein [14], (b) ability to scavenge free radicals $[18,19]$ (c) involvement in the metabolic conversion of carotenoids to retinoids [20], (d) mediation of interactions of carotenoids with topoisomerase II, an enzyme involved in cellular DNA-protein interaction [14], (e) promotion of interactions mediated via lectins [21].

Most recently, we have shown pro-apoptotic and antiinflammatory effects of saffron extract against hepatocellular carcinoma both in vitro and in vivo [11]. However, the role of the tumor suppressor p53 in saffron-induced programmed cell death has yet to be adequately explored in colorectal cancer. Apoptosis is a gene regulated phenomenon that is important both in physiological and pathological conditions. The regulatory mechanisms of apoptosis include, but are not limited to, caspases and bcl-2 family proteins [22,23]. Since more than $50 \%$ of colorectal carcinomas are characterized by a loss of p53 function, here we will analyze the antiproliferative and pro-apoptotic effects of saffron in HCT colon cancer cell lines with different p53 status.

\section{Methods}

\section{Plant material and preparation}

Stigmata of pure saffron were obtained from the Golpeech Saffron (www.golpeechsaffron.com, Register No.: 82558, Mashad, Iran) and voucher sample was preserved for reference in the herbarium of UAEU. Five hundred grams of the stigma materials were extracted at UAEU with $80 \%(\mathrm{v} / \mathrm{v})$ aqueous ethanol and the mixture was macerated for five days at $4^{\circ} \mathrm{C}$. The resulting mixture was then filtered dried under reduced pressure in a rotary evaporator at $40^{\circ} \mathrm{C}$ to give water and ethanol crude extracts.

\section{Cell culture and treatment}

Human colon cancer HCT116 cell lines (HCT wildtype and HCT p53-/-), obtained from ATCC, Manassas, VA, were maintained in RPMI and DMEM, respectively, and supplemented with $10 \%$ fetal bovine serum, penicillin (100 U/ml), and streptomycin $(100 \mu \mathrm{g} / \mathrm{ml})$ inside a humidified incubator with $5 \% \mathrm{CO}_{2}$ and $95 \%$ room air. Cells were subcultured every 4-7 days with trypsin/EDTA (1:250) (PAA Laboratory, Germany). Cells were treated with several concentrations of saffron extract for several time points.

\section{MTT cell proliferation assay}

The 3-(4,5-Dimethylthiazol-2-yl)-2,5-diphenyltetrazolium bromide (MTT), a yellow tetrazole) proliferation assay was utilized in HCT116 cell lines (HCT wildtype and HCT p53-/-) to assess the dose-dependent effect of saffron extract on cell proliferation. Cells $\left(10^{4}\right)$ were plated and grown in $200 \mu \mathrm{l}$ of growth medium in 96-well microtiter plates. After an overnight attachment period, cells were treated with varying concentrations of saffron extract $(0.25,0.5,1,2,3,4,5 \mathrm{mg} / \mathrm{ml})$ prepared from a $100 \mathrm{mg} / \mathrm{ml}$ stock solution dissolved in water for 24 and $48 \mathrm{~h}$. All studies were performed in triplicates and repeated three times independently. Cell growth was quantified by the ability of living cells to reduce the yellow dye, MTT, to a purple formazan product. Cells were incubated with MTT (Sigma-Aldrich, Steinheim, Germany) at $37^{\circ} \mathrm{C}$ in a humidified $5 \% \mathrm{CO}_{2}$ atmosphere for $2 \mathrm{~h}$. The MTT formazan product was then dissolved in DMSO, and absorbance was measured at $570 \mathrm{~nm}$ in a microplate reader.

\section{Crystal violet assay}

As a second method for determining the cytotoxicity of saffron on HCT116 cells we used the crystal violet assay. Upon solubilization, Cells $\left(7.5 \times 10^{3}\right)$ were seeded and grown in $200 \mu \mathrm{l}$ of growth medium in 96-well microtiter plates. They were allowed to attach overnight before saffron treatment as described for the MTT assay. After washing with PBS the cells were incubated and were slightly shaked at RT with $50 \mu$ l staining solution $(0.5 \%$ crystal violet, $20 \%$ methanol) which stains DNA. The plate was washed 2 times with $\mathrm{dH}_{2} \mathrm{O}$ and dried completely. The uptaken crystal violet was solubilized by addition of $200 \mu \mathrm{l}$ of methanol and 15 min incubation on a shaker. Finally, the amount of dye taken up by the monolayer was quantified by measuring the absorbance at $570 \mathrm{~nm}$ in a microplate reader. All studies were performed in triplicates and repeated three times independently.

\section{Flow cytometric analysis of DNA content}

One day before treatment, cells were seeded at a density of $1.2 \times 10^{6}$ cells per well of a 6 -well plate. After the indicated times, the cells were harvested by trypsin release, washed twice with phosphate buffered saline (PBS) resuspended in $0.5 \mathrm{ml}$ icecold $\mathrm{PBS}$ and fixed over night 
with $4 \mathrm{ml}$ ice cold $70 \%$ ethanol. Low molecular weight DNA fragments were extracted by 10 min incubation with extraction buffer $\left(9\right.$ parts $50 \mathrm{mM} \mathrm{Na} \mathrm{HPO}_{4}, 1$ part $25 \mathrm{mM}$ citric acid and $0.1 \%$ triton $\mathrm{x}-100 ; \mathrm{pH} 7.8)$. After centrifugation the cells were resuspended and incubated in the dark at RT in $0.4 \mathrm{ml}$ staining buffer $(10 \mathrm{mM}$ PIPES, $100 \mathrm{mM} \mathrm{NaCl}, 2 \mathrm{mM} \mathrm{MgCl} 2,0.1 \%$ triton $\mathrm{x}-100$; $\mathrm{pH}$ 6.8) with the addition of $250 \mu \mathrm{g}$ RNase and propidium iodide $(50 \mu \mathrm{g} / \mathrm{ml}$ final concentration). Distribution of cell cycle phases with different DNA contents was determined using a flow cytometer FACS CantoII (Becton-Dickinson, CA, USA). Sub $\mathrm{G}_{1}$ cells in flow cytometric histograms were considered apoptotic cells. Analysis of cell cycle distribution and the percentage of cells in the $G_{1}, S$, and $G_{2} / M$ phases of the cell cycle were determined using the cell cycle platform of the FlowJo software with the Watson pragmatic model (Tree Star, Ashland OR, USA).

\section{Quantification of Apoptosis by AnnexinV-PI staining}

To detect apoptosis, the AnnexinV-FLUOS kit (Roche Diagnostics, USA) was used. Cells were treated for 24 and $48 \mathrm{~h}$ with saffron extract. After washing twice in PBS, $1 \times 10^{6}$ cells were stained with $100 \mu \mathrm{l}$ annexin V staining solution, consisting of $20 \mu \mathrm{l}$ FITC-conjugated annexin $\mathrm{V}$ reagent $(20 \mu \mathrm{g} / \mathrm{ml}), 20 \mu \mathrm{l}$ isotonic propidium iodide $(50 \mu \mathrm{g} / \mathrm{ml})$, and $1000 \mu \mathrm{l}$ of $1 \mathrm{M} / \mathrm{L}$ HEPES buffer, for 15 minutes at room temperature. Cells were analyzed on a flow cytometer FACS CantoII (Becton-Dickinson, CA, USA) using a $488 \mathrm{~nm}$ excitation and 530/30 nm band pass filter for fluorescein detection and a long pass filter $2 \mathrm{P} 670 \mathrm{~nm}$ for propidium iodide detection after electronic compensation. Since positive annexin V staining indicates apoptotic and necrotic cells, propidium iodide-positive cells were used to measure late apoptotic cells and necrotic cells whereas annexin V-positive and propidium iodide-negative cells were counted as early apoptotic cells.

\section{Western Blotting}

Whole cell lysates were prepared from both HCT116 cell lines tumor cells. Protein concentration of lysates was determined with Bio-Rad Dc Protein Assay (BioRad Laboratories, Hercules, CA, USA), and $30 \mu \mathrm{g}$ proteins were loaded onto $12 \%$ SDS-polyacrylamide gel electrophoresis (voltage: $30 \mathrm{~mA}$, running time $1.5-2 \mathrm{~h}$ ). Gels were transferred to nitrocellulose membranes before immunodetection processing with antibodies against phospho-H2AX (Millipore), caspase 3, phospho-H3, PARP (all 3 Cell Signaling Technology Inc., MA, USA), LC3 (Nanotools, Germany), H3 (Actife Motif, CA, USA), cyclin B1 (Santa Cruz, CA, USA) and with secondary antibodies (antimouse or anti-rabbit IgG peroxidase conjugated; Pierce, Rockford, IL, USA). Bound antibodies were detected by incubating the blots in West Pico chemiluminescent substrate (Pierce, Rockford, IL, USA). The level of immunoreactivity was measured as peak intensity using an image capture and analysis system (GeneGnome, Syngene, UK). Hybridization with anti-GAPDH was used to control equal loading and protein quality.

\section{Statistical analysis}

Data were analyzed using the Student $t$-test to calculate the significance values; a probability value $(\mathrm{p})<0.05$ was considered statistically significant.

\section{Results}

\section{Saffron has an anti-proliferative effect in p53 isogenic HCT116 cell lines}

To determine the anti-viability effect of saffron, both cell lines were treated with various concentrations of saffron for 24 and $48 \mathrm{~h}$. MTT (3-(4,5-Dimethylthiazol-2-yl)-2,5diphenyltetrazolium bromide, a yellow tetrazole) is reduced to purple formazan in living cells and using the MTT test we can measure the viability and proliferation of cells after drug administration. Saffron reduced the proliferation of HCT116 cells in a time- and concentration-dependent manner. The most remarkable effects were observed at concentrations between 2 and $4 \mathrm{mg} / \mathrm{ml}$ (Figure $1 \mathrm{~A}$ and B). The mitochondrial function of HCT116 p53-/- cells was more efficiently diminished by the drug at doses between 1 and $4 \mathrm{mg} / \mathrm{ml}$.

Crystal violet staining was used to determine the number of viable cells after drug exposure. It confirmed that saffron significantly decreased the viability of both cell lines $(\mathrm{p}<0.05)$ at $3 \mathrm{mg} / \mathrm{ml}$ (Figure $1 \mathrm{C}$ and D). HCT116 p53 wildtype cells died significantly more than HCT116 p53-/- cells with 3 and $5 \mathrm{mg} / \mathrm{ml}$ at both time points, $24 \mathrm{~h}$ ( $26 \%$ versus $40 \%$ respectively) and at $48 \mathrm{~h}$ ( $14 \%$ versus $28 \%$, respectively) $(\mathrm{p}<0.05)$.

\section{Saffron induces a p53-dependent cell cycle arrest in HCT116 cells}

To examine the effect of saffron on cell cycle dynamics, flow cytometric analysis was performed. Figure $2 \mathrm{~A}$ and $\mathrm{B}$ showed that saffron induced a transient $\mathrm{S}$ phase arrest at $6 \mathrm{~h}$ in both cell lines and there were p53-dependent effects on cell cycle phase distribution at later time points. HCT116 p53 wildtype cells still showed a pronounced S-phase arrest at $24 \mathrm{~h}$. The HCT116 p53-/- cells, however, resumed proliferation and released cells into G2/M phase without showing a remarkable increase in Pre-G1 apoptotic cell fraction. Interestingly, HCT116 p53 wildtype cells showed a delay in S/G2 checkpoint passage returning to proliferation later at $48 \mathrm{~h}$. That was clearly shown by a significant decrease $(\mathrm{p}<0.05)$ in $\mathrm{S}$ phase and an increase in G2 phase. In contrast to HCT116 p53 -/- cells $17.4 \%$ of cells were simultaneously released from the cell cycle. This 


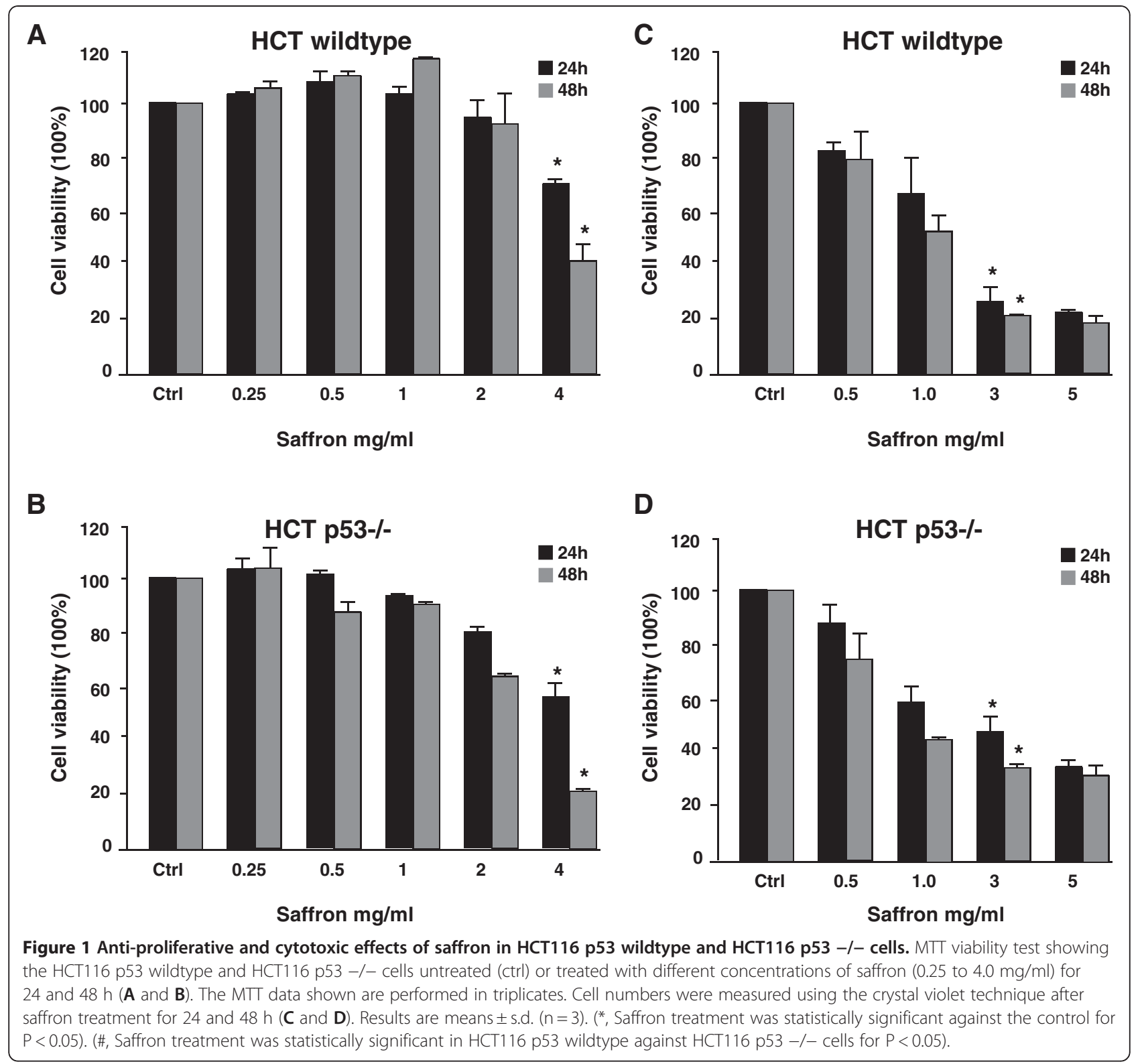

arrest of proliferation-execution process was reflected by a double S-phase peak in both cell lines but was more obvious in HCT116 p53 wildtype cells (Figure 2A and B).

Through analyzing two key regulators of G2/M arrest, namely cyclin B1 and phospho-Histone 3 (pH3), we confirmed the FACS analysis. Western blot analysis showed that there was an early 2-fold up-regulation of cyclin B1 in HCT116 p53 wildtype cells followed by a decrease to the control level at $24 \mathrm{~h}$. Also the cyclin B1 protein has nearly completely disappeared at $48 \mathrm{~h}$ after saffron treatment (Figure 2C). As expected, this decrease was associated with a down regulation of mitosis-specific $\mathrm{pH} 3$ suggesting no $\mathrm{M}$ phase transition (Figure 2C).

On the other hand, HCT116 p53-/- cells showed a continuous increase in cyclin B1 protein levels with time and finally failed to decrease the levels of cyclin B1 and $\mathrm{pH} 3$ at $48 \mathrm{~h}$. This suggests that saffron treatment causes HCT116 p53 -/- cells to enter mitosis and undergo cell death possibly at later time points (Figure $2 \mathrm{C}$ ).

\section{Saffron induces p53-dependent caspase 3 activation in HCT116 cells}

Next we confirmed apoptosis induction in the two HCT116 p53 isogenic cell lines using the Annexin-PI staining. We showed a similar time-dependent increase in the number of apoptotic cells after saffron treatment in both cell lines compared to the basal apoptosis levels (Figure 3A and B). However, the early apoptotic fraction (Annexin-positive and PI-negative) was significantly higher in HCT116 wildtype cells $(\mathrm{p}<0.05)$ at $48 \mathrm{~h}(12.8 \%$ 


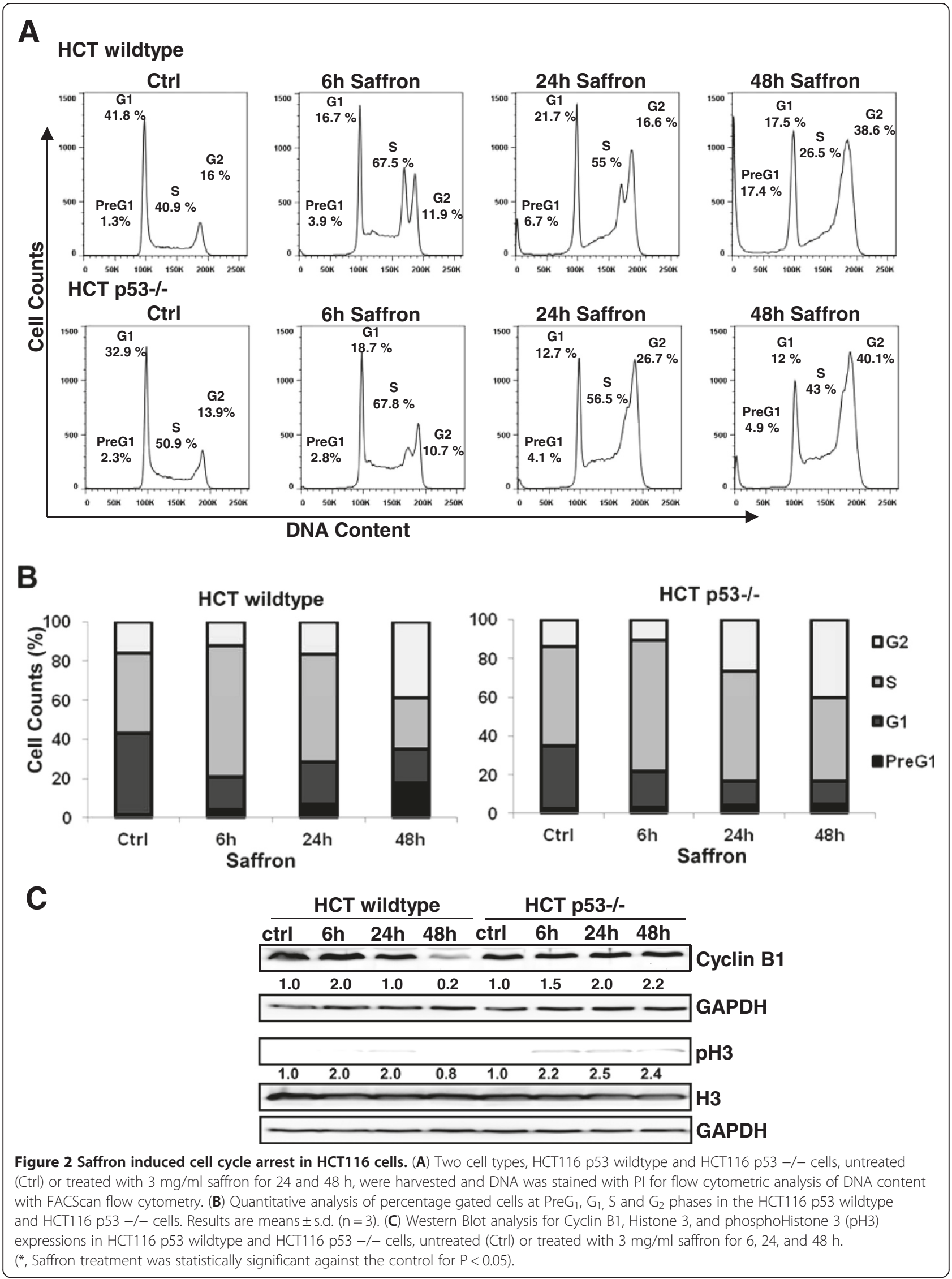




\section{A}

HCT wildtype
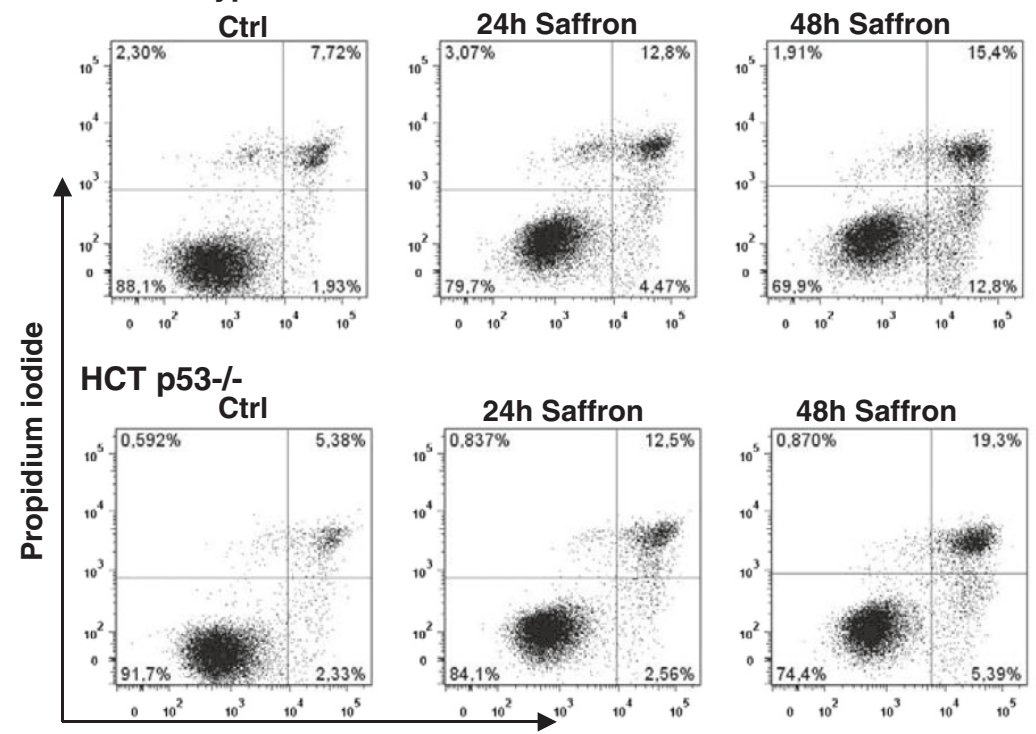

Annexin V-FITC
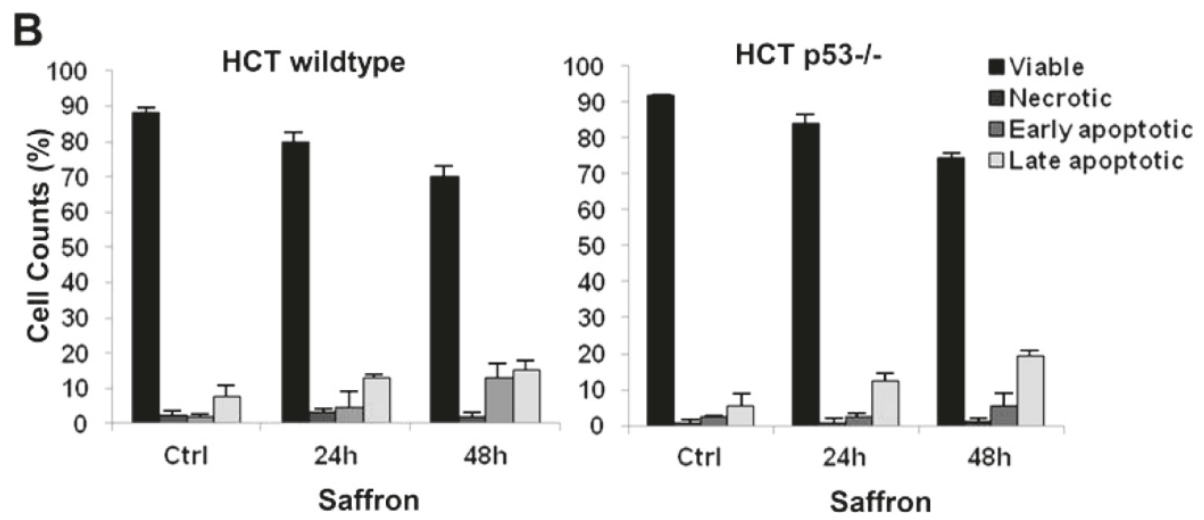

Figure 3 Pro-apoptotic effects of saffron. (A) Annexin-PI measurements of untreated cells (Ctrl) and the two cell types, HCT116 p53 wildtype and HCT116 p53 -/- cells, treated with $3 \mathrm{mg} / \mathrm{ml}$ saffron for 24 and $48 \mathrm{~h}$. The profile represents Annexin-V-FITC staining in $x$ axis and PI in y axis. (B) Quantitative analysis of percentage gated for viable, necrotic, early apoptotic, and late apoptotic HCT116 p53 wildtype and HCT116 p53 - / - cells treated with $3 \mathrm{mg} / \mathrm{ml}$ saffron for 24 and $48 \mathrm{~h}$. Results are means \pm s.d. $(n=3)$. (*, Saffron treatment was statistically significant in HCT116 p53 wildtype against HCT116 p53 -/- cells for $\mathrm{P}<0.05)$

versus 5.4\%, respectively). Examining the caspase activation, we indicated a higher increase of the cleaved caspase 3 products in HCT116 p53 wildtype cells. This was accompanied by an increase in cleavage of its target PARP (Figure 4A) showing more apoptosis and suggesting that this saffron-induced DNA-damage is mediated through the gate keeper $\mathrm{p} 53$. Indeed, there was an up-regulation of $\mathrm{p} 53$ protein reaching 4.6 -fold values at $48 \mathrm{~h}$. In parallel, there was a remarkable up-regulation in DNA damage after saffron treatment as reflected by an increase in protein levels of $\gamma \mathrm{H} 2 \mathrm{AX}$, a sensor of DNA double strand breaks (Figure 4B). But HCT116 p53 -/- cells showed an increase in $\gamma \mathrm{H} 2 \mathrm{AX}$ already after $24 \mathrm{~h}$ and the levels where approximately 2.5-fold higher compared to the HCT116 p53 wildtype cells at 48 h (Figure 4B).

\section{Saffron induces a massive autophagic cell death in HCT116 p53 -/- cells}

We next ask the question, what is protecting HCT116 p53 - / - cells from apoptosis after the observed severe DNA damage. In order to address this, we investigated whether saffron induces hallmarks of autophagy in a p53-dependent manner. The level of LC3-II, a protein that accumulates as a result of increased autophagosome formation [24], was assessed. Indeed, saffron induced a more pronounced conversion from LC3-I to LC3-II in 


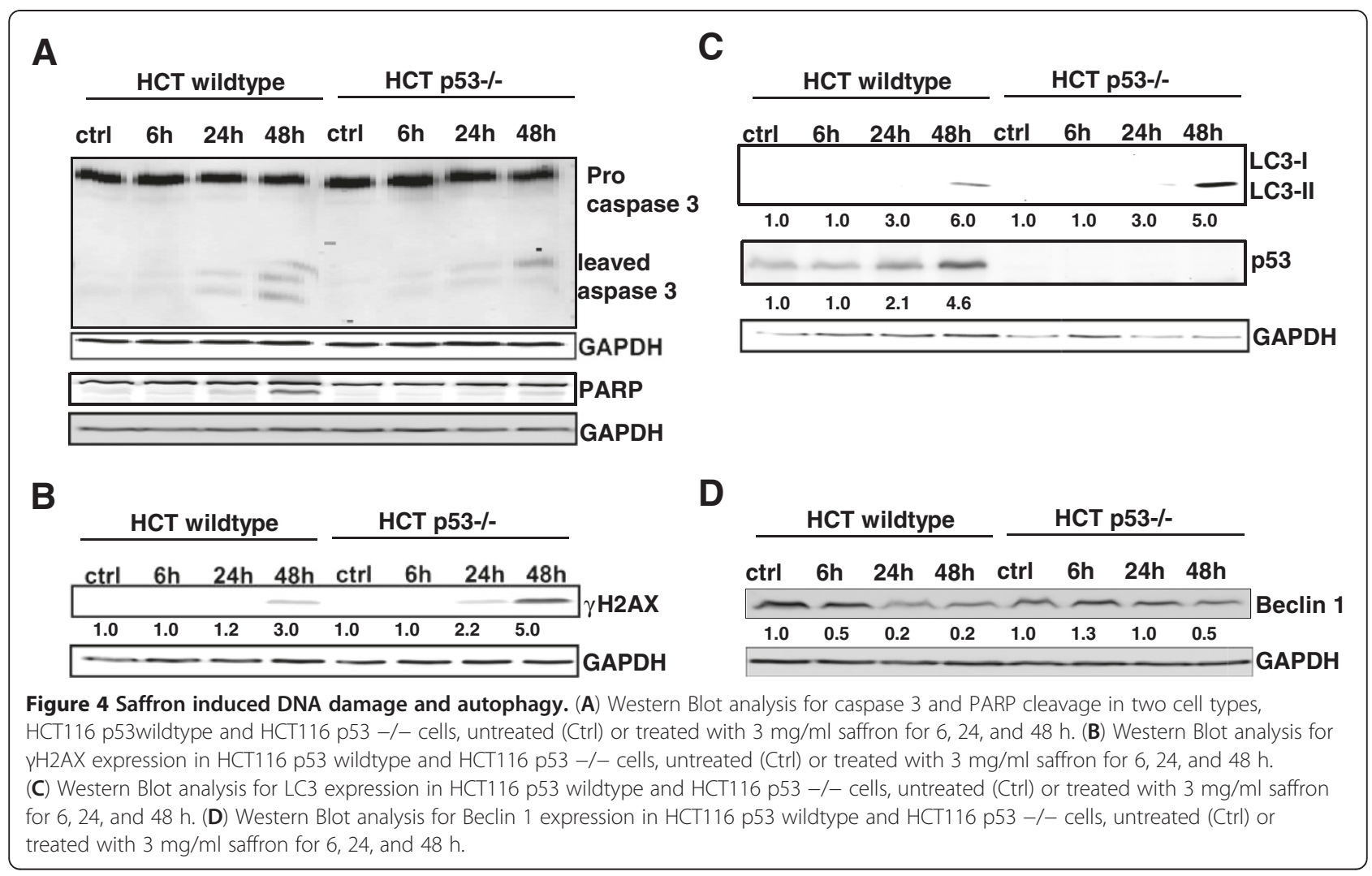

HCT116 p53-/- cells than in HCT116 p53 wildtype cells after $24 \mathrm{~h}$ and $48 \mathrm{~h}$, (Figure $4 \mathrm{~B}$ ), although there was a higher basal rate of autophagy in HCT116 p53-/cells. Studying Beclin 1, which is known to interfere with autophagic vesicle formation, allowed us to find a higher beclin 1 protein levels in the HCT116 p53 -/- cells after saffron treatment. We, therefore, suggest that autophagic disposal of damaged cell debris might reduce or delay the cell death induction after saffron treatment in HCT116 p53 -/- cells.

\section{Discussion}

Natural products have long been used to prevent and treat diseases including cancers and might be good candidates for the development of anti-cancer drugs [25]. Saffron, a commonly-used spice and food additive, is known for its anti-cancer and anti-tumor properties [12-16].

Because most of the in vivo studies were interested in the isolated bioactive compounds of saffron, little research has been done to examine anti-cancer properties of saffron in its natural form. Tavakkol-Afshari and colleagues [26] reported that 96\% ethanol saffron extract is selectively cytotoxic against epithelial-like human hepatocellular carcinoma cells (HepG-2) as well as human cervical carcinoma cells (HeLa) but nontoxic towards normal mouse fibroblast cells (L929). The additive and synergistic effects among the different phytochemicals in saffron however, may enhance its anti-carcinogenic properties [27]. Based on those reports, more studies are necessary to determine the beneficial effects of saffron in its natural form using human subjects [9].

In this study, we analyzed the possible role of p53 in the cytotoxic, anti-proliferative and pro-apoptotic effects of saffron on two p53 isogenic HCT116 cell lines. Cell proliferation inhibition test using MTT viability assay as well as crystal violet staining confirmed that ethanolic extract of saffron has cytotoxic activity against HCT116 cells. The present results were in agreement with previous reports indicating that saffron and its ingredients possessed anti-tumor and anti-cancerogenic activities and have no cytotoxic effect on non-malignant cells $[9,26,27]$. Consistent with our previous study on HepG-2 cells [11], saffron extract induced a significant toxicity in HCT116 after 48 h. Similarly, HCT116 cells were shown to have a significant higher sensitivity to saffron extract compared to other colorectal cancer cell lines; SW-480 and HT-29 [27]. The observed apoptotic induction in HCT116 p53 wildtype cells obviously resulted from DNA damage as reflected by the up-regulation of the double-stranded DNA breakage marker, $\gamma \mathrm{H} 2 \mathrm{AX}$, suggesting an additional role of saffron in sensitizing cancer cells to the effects of other chemotherapeutics.

In cancer chemotherapy, cancer programmed cell death has been emphasized and shown to be mediated 
by many factors. The tumor suppressor p53 mediates apoptosis, cell cycle regulation and DNA repair in response to a wide range of cellular stresses. Mutations in p53 have been found in almost $50 \%$ of all colorectal cancers worldwide [28] and at high frequencies in many different cancers [2]. We investigated whether saffron treatment induced p53-dependent cell cycle arrest, apoptosis or autophagy in HCT116 cell lines. Sluggish $\mathrm{S}$-phase transit was a remarkable effect of saffron in both cell lines. To better understand the subsequent G2/ $\mathrm{M}$ arrest, we studied the Cyclin B1 protein levels because a proper Cyclin B1 regulation is known to be necessary for the entry into mitosis [29]. The low Cyclin $\mathrm{B} 1$ and pH3 levels in HCT116 p53 wildtype cells reflect that saffron induces a full G2 arrest after $48 \mathrm{~h}$ of treatment without allowing the cells to enter the $M$ phase. Cells without p53 but high Cyclin B1 and pH3 levels clearly enter the $M$ phase and further accumulate severe saffron-induced DNA damage as reflected by the increase in $\mathrm{pH} 2 \mathrm{AX}$ protein levels.

The role of p53 in autophagy, programmed cell death form II, remains controversial with studies suggesting presence of $\mathrm{p} 53$, as well as absence of $\mathrm{p} 53$, as inducer of autophagy [30]. In the present study, both cell lines showed accumulation of autophagosomes after saffron treatment monitored by the increase in the lipidated LC3-II protein. There are two forms of LC3 proteins: the cytoplasmic LC3-I and the autophagosome membrane-bound LC3-II form. The failure in repairing the massively damaged DNA by a lack in p53 led to a significant higher LC3-II proportion after saffron treatment. This effect has been observed also after prolonged starvation [31] and has been interpreted as an increased functional autophagy in p53 -/- cells. In the absence of p53, autophagosome recycling is possibly less effective and the observed increase in LC3-II forms after saffron treatment of HCT116 p53 -/- cells could also reflect the aberrant accumulation of static autophagosomes. This would slow down the autophagic flux, cause accumulation of aberrant protein intermediates and would have a later effect on apoptosis. Thus autophagy would ultimately lead to a delay in apoptosis and protection of cells from cell death. The time interval observed in our study suggests a rather pro-survival role of saffron-induced autophagy. Indeed, the role of autophagy in cancer development is complex, as it has been implicated in both tumor survival and tumor cell death $[32,33]$. At the present time, we still do not know the genes responsible for inducing autophagy in the p53 - / - cells after saffron treatment. We could however speculate that a p53 homolog such as p73 may have been activated in p53-/- cells and modulated autophagy [34] or mild apoptosis. In this regard, it has been shown that p73 interacts with p53-responsive elements and induces transcription of p53-inducible genes [35].

Despite the accumulating evidence demonstrating that saffron may be a promising cancer therapy agent, mechanisms of saffron anti-cancer actions are still largely unknown. Many proposed mechanisms have been reported. Bathaie and colleagues [36] found that saffron carotenoids directly bind to DNA minor grooves and induce conformational changes of targeted DNA. The induction of apoptosis by saffron has been reported to play an essential role in the death of human hepatocellular carcinoma cells and HeLa cells $[11,26]$. Although saffron demonstrates potential as an anti-cancer drug, further research is needed to elucidate the mechanisms and effects of saffron in p53 -/tumors. The therapeutic endpoint in p53 -/- tumor cells has to be clarified using long term assays and in vivo models.

\section{Conclusion}

In conclusion, data from this study suggests that saffron shows a p53-dependent efficacy in colorectal cancer. There seems to be a pro-survival role of autophagy in saffron-induced damage response in p53 -/- tumors. Considering the popularity of herbal use in cancer patients, saffron and especially its active ingredients should be investigated further as a viable option in the treatment of colorectal cancer.

\section{Competing interests}

The authors declare that they have no competing interests.

\section{Authors' contributions}

RSS designed the study and supervised the experimental work. She helped with interpreting the data and writing the manuscript. KB wrote the manuscript and designed the Figures. $\mathrm{KB}$ and SD have done the cell culture experiments and Western Blot analyses. AA supplied the saffron extract and other reagents and was involved in drafting the manuscript and has reviewed the final version prior publication. JSL performed the FACS PI and Annexin-PI analysis and prepared the corresponding figures. All authors read and approved the final manuscript.

\section{Acknowledgments}

This study was funded in-part by Emirates Foundation Grant \# 2009-079 for AA. Authors are also grateful to Adrian Koch for his excellent technical assistance.

\section{Author details}

'Biology Department, Faculty of Science, UAE University, Al-Ain, United Arab Emirates. ${ }^{2}$ Experimental Tumorpathology, Institute of Pathology, University of Erlangen-Nürnberg, Universitätsstrasse 22, Erlangen 91054, Germany.

${ }^{3}$ Department of Zoology, Cairo University, Cairo , Egypt.

Received: 4 November 2011 Accepted: 6 March 2012

Published: 28 May 2012

\section{References}

1. Cantero-Muñoz P, Urién MA, Ruano-Ravina A: Efficacy and safety of intraoperative radiotherapy in colorectal cancer: a systematic review. Cancer Lett 2011, 306:121-133.

2. Harrison $\mathrm{S}$, Benziger $\mathrm{H}$ : The molecular biology of colorectal carcinoma and its implications: a review. Surgeon 2011, 9:200-210. 
3. Facchini PJ: Alkaloid biosynthesis in plants: biochemistry, cell biology, molecular regulation and metabolic engineering. Ann Rev Plant Physiol Plant Mol Biol 2001, 52:29-66.

4. Holstein SA, Hohl RJ: Isoprenoids: remarkable diversity of form and function. Lipids 2004, 34:293-309.

5. Iriti M, Faoro F: Plant defense and human nutrition: the phenylpropanoids on the menu. Curr Top Nutr Res 2004, 2:47-65.

6. Amin A, Buratovich M: The Anti-cancer Charm of Flavonoids: a cup-of-tea will do! Recent Pat Anticancer Drug Discov 2007, 2:109-117.

7. Deo B: Growing saffron - the world's most expensive spice. Crop Food Res 2003, 20:1-4.

8. Chryssanthi DG, Dedes PG, Karamanos NK, Cordopatis P, Lamari FN: Crocetin Inhibits Invasiveness of MDA-MB-231 Breast Cancer Cells via Downregulation of Matrix Metalloproteinases. Planta Med 2011, 77:146-151.

9. Melnyk JP, Wang S, Marcone MF: Chemical and biological properties of the world's most expensive spice: saffron. Food Res Inter 2010, 43:1981-1989.

10. Ghadrdoost B, Vafaei AA, Rashidy-Pour A, Hajisoltani R, Bandegi AR, Motamedi F, Haghighi S, Sameni HR, Pahlvan S: Protective effects of saffron extract and its active constituent crocin against oxidative stress and spatial learning and memory deficits induced by chronic stress in rats. Eur JPharmacol 2011, 667:222-229.

11. Amin A, Hamza A, Bajbouj K, Ashraf SA, Daoud S: Saffron: a potential candidate for a novel anti-cancer drug against hepatocellular carcinoma. Hepatology 2011, 54:857-867.

12. Abdullaev Fl, Espinosa-Aguirre JJ: Biomedical properties of saffron and its potential use in cancer therapy and chemoprevention trials. Cancer Detect Prev 2004, 28:426-432.

13. Deng $Y$, Guo ZG, Zeng ZL, Wang Z: Studies on the pharmacological effects of saffron (Crocus sativus L.) - a review. Zhongguo Zhong Yao Za Zhi 2002, 27:565-568.

14. Mousavi SH, Tavakkol-Afshari J, Brook A, Jafari-Anarkooli I: Role of caspases and Bax protein in saffron-induced apoptosis in MCF-7 cells. Food Cheml Toxicol 2009, 47:1909-1913.

15. Nair SC, Kurumboor SK, Hasegawa JH: Saffron chemoprevention in biology and medicine: a review. Cancer Biother 1995, 10:257-264.

16. Nair SC, Pannikar B, Panikkar KR: Antitumour activity of saffron (Crocus sativus). Cancer Lett 1991, 57:109-114.

17. Das I, Das S, Saha T: Saffron suppresses oxidative stress in DMBA-induced skin carcinoma: a histopathological study. Acta Histochem 2010, 112:317-327.

18. Premkumar K, Abraham SK, Santhiya ST, Ramesh A: Protective effects of saffron (Crocus sativus Linn.) on genotoxins-induced oxidative stress in Swiss albino mice. Phytother Res 2003, 17:614-617.

19. Zheng YQ, Liu JX, Wang JN, Xu L: Effects of crocin on reperfusion-induced oxidative/nitrative injury to cerebral microvessels after global cerebral ischemia. Brain Res 2007, 1138:86-94.

20. Dufresne C, Cormier F, Dorion S: In vitro formation of crocetin glucosyl esters by Crocus sativus callus extract. Planta Med 1997, 63:150-153.

21. Abdullaev Fl, Gonzalez De Mejia E: Antitumor activity of natural substances: lectins and saffron. Arch Latinoam Nutr 1997, 47:195-202.

22. Green DR, Reed JC: Mitochondria and apoptosis. Science 1998 281:1309-1312.

23. Scorrano L, Oakes SA, Opferman JT, Cheng EH, Sorcinelli MD, Pozzan T, Korsmeyer SJ: BAX and BAK regulation of endoplasmic reticulum Ca2+: a control point for apoptosis. Science 2003, 300:135-139.

24. Rubinsztein DC, Cuervo AM, Ravikumar B, Sarkar S, Korolchuk V, Kaushik S, Klionsky DJ: In search of an "autophagomometer". Autophagy 2009, 5:585-589.

25. Liu RH: Potential synergy of phytochemicals in cancer prevention: Mechanism of action. J Nutrition 2004, 134:3479S-3485S

26. Tavakkol-Afshari J, Brook A, Mousavi SH: Study of cytotoxic and apoptogenic properties of saffron extract in human cancer cell lines. Food Chem Toxicol 2008, 46:3443-3447.

27. Aung HH, Wang CZ, Ni M, Fishbein A, Mehendale SR, Xie JT, Shoyama CY, Yuan CS: Crocin from Crocus sativus possesses significant antiproliferation effects on human colorectal cancer cells. Exp Oncol 2007, 29:175-180.

28. Kern A, Taubert H, Scheele J, Rudroff C, Mothes H, Kappler M, et al: Association of p53 mutations, microvessel density and neoangiogenesis in pairs of colorectal cancers and corresponding liver metastases. Int J Oncol 2002, 21:243-249.

29. Yuan J, Yan R, Krämer A, Eckerdt F, Roller M, Kaufmann M, Strebhardt K: Cyclin B1 depletion inhibits proliferation and induces apoptosis in human tumor cells. Oncogene 2004, 23:5843-5852.

30. Levine B, Abrams J: p53: the Janus of autophagy? Nat Cell Biol 2008, 10:637-639.

31. Scherz-Shouval R, Weidberg H, Gonen C, Wilder S, Elazar Z, Oren M: p53dependent regulation of autophagy protein LC3 supports cancer cell survival under prolonged starvation. PNAS 2010, 107:18511-18516.

32. Hippert MM, O'Toole PS, Thorburn A: Autophagy in cancer: good, bad, or both? Cancer Res 2006, 66:9349-9351.

33. Jun $L$, Zhenghong $Q$, Zhongqin $L$ : The prosurvival role of autophagy in Resveratrol-induced cytotoxicity in human U251 glioma cells. BMC Caner 2009, 9:215-224.

34. Vilgelm A, El-Rifai W, Zaika A: Therapeutic prospects for $p 73$ and p63: rising from the shadow of p53. Drug Resist Updat 2008, 11:152-163.

35. Crighton D, O'Prey J, Bell HS, Ryan KM: p73 regulates DRAM-independent autophagy that does not contribute to programmed cell death. Cell Death Differ 2007, 14:1071-1079.

36. Bathaie SZ, Bolhasani A, Hoshyar R, Ranjbar B, Sabouni F, Moosavi-Movahedi A: Interaction of saffron carotenoids as anticancer compounds with ctDNA Oligo (dG.dC)15, and Oligo (dA.dT)15. DNA Cell Biol 2007, 26:533-540.

doi:10.1186/1472-6882-12-69

Cite this article as: Bajbouj et al:: The anticancer effect of saffron in two p53 isogenic colorectal cancer cell lines. BMC Complementary and Alternative Medicine 2012 12:69.

\section{Submit your next manuscript to BioMed Central and take full advantage of:}

- Convenient online submission

- Thorough peer review

- No space constraints or color figure charges

- Immediate publication on acceptance

- Inclusion in PubMed, CAS, Scopus and Google Scholar

- Research which is freely available for redistribution
C) Biomed Central 